Wolfgang Fauth

\title{
Jao-Jahwe und seine Engel
}

Jahwe-Appellationen und zugehörige Engelnamen in griechischen und koptischen Zaubertexten

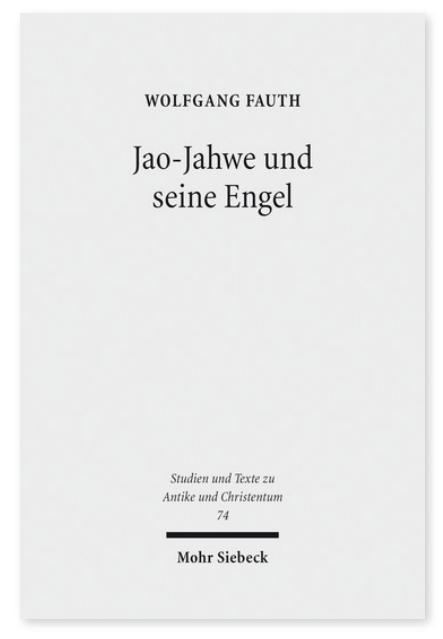

2014. XI, 133 Seiten. STAC 74

ISBN 978-3-16-152708-1

DOI 10.1628/978-3-16-152708-1

eBook PDF 94,00€

ISBN 978-3-16-152222-2

fadengeheftete Broschur $94,00 €$
Die Onomastik spätantiker Zaubertexte präsentiert eine Vielzahl von Varianten des jüdischen Gottesnamens Jahwe, darunter primär die graphische Form J/lao. Wolfgang Fauth befasst sich mit ihrer morphologischen Eigenart, ihrer Erweiterung oder ihrem Ersatz durch die Jao-Appellative Sabaoth, Adonai, Eloai, Abrasax, sowie durch Komposita (Jasabaoth) oder Intensiva (Arbatha Jao). Er beleuchtet die Ergänzung dieses Arrangements aus dem reichhaltigen Fundus jüdisch-hebräischer Engelnamen nebst dem daraus abzuleitenden Rangwechsel Jao-Jahwes zwischen einem Status angelicus und der Hochposition des Allherrschers (Pantrokrator). Aus dem nominalem Kontakt mit graecoägyptischen Gottheiten und der personalen Fusion mit dem Salvator Jesus Christus ergibt sich ein komplexes Gesamtbild seines Wesens im Umfeld magischer Anrufungen, Beschwörungen und Verfluchungen, erzeugt von speziellen subliterarischen Dokumenten der antiken Spätzeit.

Wolfgang Fauth Geboren 1924; 1949-53 Studium der Klassischen Philologie sowie der antiken und orientalischen Religionsgeschichte an der Universität Göttingen; 1953 Promotion; 1973 Habilitation; 1976-89 Professor für Klassische Philologie, antike Mythologie und Religion; seit 1989 emeritiert.

Jetzt bestellen:

https://mohrsiebeck.com/buch/jao-jahwe-und-seine-engel-9783161527081?no_cache=1

order@mohrsiebeck.com

Telefon: +49 (0)7071-923-17

Telefax: $+49(0) 7071-51104$ 